\title{
EL REPUBLICANISMO EN ALICANTE: FEDERALISTAS Y MODERADOS (1868-1872)
}

Rosa ANa GutierRez LLORET

Universidad de Alicante

El objeto del presente trabajo, con las limitaciones que nos impone su propia naturaleza, es el de iniciar una aproximación al estudio de una de las formaciones políticas que más importancia han tenido en la historia contemporánea alicantina: el partido republicano.

Vamos a tratar aquí de analizar los orígenes de una polémica en el seno del partido que le llevará en 1873 a la clara división en dos tendencias que llevan implícitas diferentes alternativas políticas y que ya en la Restauración conduce a la escisión del partido republicano en varias organizaciones diferentes.

Hemos partido del sexenio democrático, momento clave en el proceso de consolidación del estado liberal burgués en España, que coincide con la irrupción del republicanismo como fuerza importante en la escena política. Tradicionalmente la historiografía española contemporánea ha señalado la "Declaración de la Prensa" como el inicio del resquebrajamiento de la unidad republicana, pero los primeros síntomas de división se empiezan a evidenciar desde 1869 en los propios orígenes de la estructuración del partido.

Veremos como desde el fracaso de la sublevación republicana de 1869 se inicia un proceso de disgregación del republicanismo en dos tendencias y como progresivamente los republicanos moderados, cuyo líder será Eleuterio Maisonnave, se convierten en la fracción hegemónica en el partido republicano de Alicante. 
Como fuente documental hemos utilizado la prensa republicana alicantina, en donde ambas tendencias, moderados y federalistas, polemizaron acaloradamente sobre sus posturas y diferencias políticas.

\section{ORGANIZACION DEL PARTIDO REPUBLICANO EN ALICANTE}

Las ideas republicanas se fueron progagando rápidamente desde la revolución del 1868 con el reconocimiento de las libertades fundamentales por el Gobierno Provisional ${ }^{1}$. Desde octubre de 1868, tras la escisión del partido demócrata, el republicanismo se habia extendido por las ciudades mediterráneas pero no podía considerarse aún un partido político organizado.

Los republicanos alicantinos emprenden la organización del partido tomando como base los clubs, que actuarían como verdaderas agrupaciones políticas aglutinando diferentes sectores de la población. En ellos se reunían artesanos, intelectuales, obreros y determinados sectores de la burguesía que sociológicamente formarán la militancia republicana.

Esta embrionaria organización estaba configurada por los clubs coordinados entre sí por un Comité Local que dependía de un Comité Provincial denominado Republicano Federal de Alicante. En la ciudad se van a empezar a fundar clubs republicanos desde el mes de noviembre que utilizan la prensa, las proclamas, las manifestaciones y reuniones como vehículo de expresión ideológica y medio para el aumento de la militancia en el partido.

Uno de los primeros clubs republicanos de Alicante se constituyó con el nombre de "Club Republicano Federalista de Los Radicales" presidido por el federalista Froilán Carvajal y del

1 Manifiesto del Gobierno Provisional a la Nación dado en Madrid a 25 de octubre de 1868, en LópEz-CORDÓN, M. V., La revolución de 1868 y la I República, Madrid, 1976, págs. 107 y ss. 
que era vicepresidente José Marcili Oliver, conocido intransigente y propietario del diario "La Revolución" de Alicante 2 .

En 1870 el federalista Roque Barcia fue nombrado socio honorario del club "Los Radicales" y de los otros dos tambień de carácter federal, el del distrito del Carmen dirigido por el artesano Bartolomé Pons y el "Club Republicano Propagandista" del barrio de San Antón presidido por Vicente López ${ }^{3}$.

Estos clubs, que por su actividad son los más importantes, sirven de centro de reunión a los grupos más combativos y extremistas del federalismo alicantino y cuyos grupos dirigentes participaron como figuras clave en los sucesos federales de 1869, 1870 y 1873.

Además de estos centros republicanos, Alicante contaba con varias organizaciones más: el «Club Republicano Federalista de Alicante", dirigido por Manuel Lozano; "Círculo Republicano", presidido por Mas Dolz; "Club Marítimo Republicano Federal", dirigido por José Navarro; "La Propaganda Republicana»; el club "lgualdad, Libertad y Fraternidad", y el "Club Federalista" 4. Cabe destacar la creación del "Club Republicano Femenino" en julio de 1869 que fue el segundo que se abrió en España, este club respondía a las necesidades de organización de las casi cuatro mil operarias de la Fábrica de Tabacos y estaba dirigido por Rita Ballester y Teresa Martínez ${ }^{5}$.

También se abrió un club para organizar a la juventud republicana de Alicante. Este club, presidido por Juan Ramos, Ilevó a cabo una campaña de prensa para pedir el derecho al sufragio para los mayores de veinte años ${ }^{6}$.

2 La Revolución, periódico republicano federal de Alicante, 3 de noviembre de 1868.

3 Ramos V., Crónica de la provincia de Alicante, Alicante, 1979, pág. 394.

4 Ibídem, pág. 394.

5 La Revolución, 7 de julio de 1869.

6 Ibídem, 31 de enero de 1869. 
En los centros republicanos se impartían enseñanzas sobre diversos temas de actualidad, existían libros de consulta para lectores potenciales y se daban toda clase de conferencias con el propósito de «ilustrar» a las clases jornaleras e incluso se llegaban a impartir clases de primaria de forma gratuita para todas las personas que lo solicitaran. Los republicanos pensaban que el alcance de sus propuestas dependía directamente de que el pueblo tomara concienca de la necesidad del progreso social y político, para lo cual era imprescindible la educación permanente?

El primer Comité Local del partido republicano de Alicante estuvo presidido por Manuel Ausó y Monzó que en 1870 fue sustituido por Primitivo Carreras. Al frente del Comité Republicano Federal estaba Francisco García López.

Como vemos, desde los orígenes de su estructuración política, el partido republicano se va a configurar como el primer partido de masas de la historia de España. La revolución del 68 tuvo como consecuencia inmediata la irrupción en la vida política de una serie de sectores de la pequeña burguesía y capas populares que hasta entonces habían estado marginados de la escena política y que ahora, utilizando como medio de participación al partido republicano, intervendrán más activamente en la politica del pais, aunque la creación de la sección española de la Internacional pronto llevará a una diversificación de la opción popular.

En los primeros meses de 1869 en el partido republicano se dará una total unidad y cohesión frente a la opción monárquica apoyada por el partido progresista; para los republicanos la democracia sólo podía implantarse en España con la República. Esta oposición a la política pro-monárquica fue contestada por el Gobierno con crecientes medidas represivas que no sólo se concretaron en períodos electorales sino que tuvieron una mayor incidencia, así se explica la persecución de que fueron objeto algunos republicanos alicantinos como Froilán Carvajal, per-

7 Ibídem, 1 de febrero de 1870. 
seguido por haber participado en diversas revueltas durante el régimen borbónico ${ }^{8}$.

El problema de organización del movimiento republicano residia en la dificultad de centralizar un movimiento cuyo apoyo social procedía fundamentalmente de la periferia peninsular y cuyo núcleo ideológico era el federalismo, lo que se tradujo en una disociación entre el trabajo parlamentario y el trabajo a nivel provincial que respondía a unos propósitos más localistas.

Con la política de los pactos federales de 1869 la iniciativa del movimiento federal pasa de la dirección central del partido a los federales de provincia y su inicio será el Pacto Federal de Tortosa firmado en mayo de 1869, en cuyo artículo cuarto se señala un posible alzamiento en caso de que al implantarse la monarquía peligrasen los derechos conseguidos tras el derrocamiento de Isabel $\mid{ }^{9}$.

Este pacto intentaba agrupar a las regiones que constituían la Antigua Corona de Aragón y representaba una tentativa de formular un anteproyecto de constitución federal. Su elaboración fue dirigida por los principales federalistas de las regiones que la integraban, dejando totalmente al margen a la dirección del partido, integrada en su mayoría por los diputados a Cortes. Estos, temiendo que se produjera una escisión en el partido, se apresuraron a suscribir los Pactos de Tortosa, publicando una carta en la que aceptaban los acuerdos pero llamaban al orden y la legalidad:

Continuad, pues, amigos, en la propaganda pacífica de nuestras fuerzas (...) y para triunfar tenemos libres las reuniones como libre la prensa, libre la tribuna y en nuestras manos el grande instrumento del progreso, el sufragio universal ${ }^{10}$.

8 Ibídem, 25 de marzo de 1869.

9 LoPez.Cordón, M. V., op. cit., págs. 132 y 133.

10 Los diputados republicanòs de Aragón, Cataluña y Valencia a los firmantes del Pacto Federal de Tortosa; veáse La Revolución, 1 de junio de 1869. Entre los firmantes figuraban junto a Figueras, Castelar y Pi, los diputados por Alicante, E. Maisonnave, A. Albors y E. Santamaría. 
Poco después el Comité Republicano Federal de la provincia de Alicante se dirige a sus correligionarios para defender el Pacto de Tortosa como principio básico de la organización del partido y la federación:

Nuestros hermanos de Aragón, Cataluña y Valencia, coaligados por la reunión que con el nombre del PACTO FEDERAL DE TORTOSA, celebraron el dia 18 del pasado Mayo en la citada ciudad, aprobaron las bases para completar la organización del partido republicano, y el Comité Provincial de Alicante, adherido espontáneamente a aquellos acuerdos, invita a sus correligionarios de la provincia para que le ayuden en esta obra, cobijándose todos bajo la bandera elevada de la siempre invicta ciudad de Tortosa.

El Comité Provincial, inspirándose en las ideas vertidas en la reunión citada, espera que sus correligionarios de la provincia secundarán sus deseos para realizar muy pronto tal vez el gran lazo federal entre todos los republicanos de España ${ }^{11}$.

Tomando como modelo este Pacto se firmarán otros similares en Córdoba, Valladolid, Eibar y La Coruña, pero éstos carecian de la solidez del primero. La dirección del partido, consciente de la posiblilidad de que el movimiento adquiriese unas dimensiones tan grandes que no pudiese ser controlado, buscó una solución de compromiso y a instancias de Pi y Margall se firmó el Pacto Nacional en junio de 1869. Este intento de centralización de la vida política del partido resultará ineficaz pues fue necesario hacer concesiones a los pactos regionales y dentro de la organización republicana ya existían síntomas de un distanciamiento entre grupos que empezaban a presentar diferencias políticas e ideológicas.

\section{LA SUBLEVACION FEDERAL DE 1869}

En septiembre y octubre de ese año se van a producir las insurrecciones federales que provocarán modificaciones dentro del partido y en la política que seguía hasta entonces. El motor. de la rebelión fue el malestar político que se evidenciaba en las filas republicanas por la creciente desilusión ante las posiciones de hegemonía, que mantenían los monárquicos desde 1868, y

11 La Revolución, 26 de junio de 1869. 
que suponia el desplazamiento del poder de las tendecias más radicales de la revolución. Esto quedaba patente en un texto de la época que analiza las causas que llevaron a los republicanos a alzarse en armas:

En cambio el partido republicano que ha prestado su programa, su esencia, sus elementos todos, al movimiento de Septiembre, se ha visto postergado, arrojado de todas partes, rodeado de asechanzas y de lazos, perseguido y combatido sin cesar.

En Septiembre del 68, llevábamos a hombros a los libertadores de España, en Octubre del 69, esos mismos hombres han manchado nuestra frente con la saliva de su desprecio y han arrojado a nuestros pies el veto de su cinismo.

En Septiembre del 68, les vitoreábamos y les ayudábamos a sentarse sobre nuestras espaldas, en Octubre del 69, nos han coartado los derechos que habiámos conquistado con nuestra sangre y nos han ametrallado impunemente en las calles ${ }^{12}$.

Este sentimiento de frustración política irá originando en el partido un estado de opinión favorable a la insurrección armada que se veía alentado por el mito de la "revolución espontánea» y por el convencimiento de que los monárquicos no les iban a permitir nunca la llegada al poder por medios legales y parlamentarios.

En Alicante se sublevaron varias partidas republicanas. La más importante era dirigida por Froilán Carvajal, cabeza visible del sector republicano intransigente en la provincia, y las otras partidas que actuaron por las comarcas alicantinas fueron dirigidas por Tomás Bertomeu y Francisco Samper Palloc quienes llegaron a implantar una Junta revolucionaria en Alcoy ${ }^{13}$. La sublevación federal tuvo un relativo eco en el País Valenciano, se centró principalmente en la ciudad de Valencia que Ilegó a ser bombardeada ${ }^{14}$.

12 Gimeno y Cabañas, A., El Partido Republicano de Valencia ante la Historia, memoria extensa y detallada de los sucesos de octubre de 1869 , con relación exacta e imparcial de las circunstancias que los motivaron, Valencia, 1870, pág. 8.

13 La Revolución, 17 y 18 de octubre de 1869; El Correo de España, Diario de Noticias, Alicante, 20 de octubre de 1869.

14 Veáse Gimeno y Cabaña, A., op. cit., pág. 133. 
Las autoridades civiles y militares tomaron todas las medidas represivas a su alcance para acabar con los insurrectos, medidas de gran dureza si las comparamos con la importancia real del movimiento insurreccional en las comarcas de Alicante. En realidad, esta represión fue utilizada por el Gobierno para contrarrestar la influencia del republicanismo en la vida política local y los republicanos fueron conscientes de ello:

Se cerraron loa clubs de orden de la autoridad, pero ¿ha sucedido asi con todas las sociedades políticas? Se ha faltado a la justicia ${ }^{15}$.

Casi no quedan ya periódicos ni corporaciones republicanas.

Ocurre lo que no ha ocurrido nunca.

iY así creen esos pobres hombres acabar con una idea, que ahora nace, y que a través de cuantas dificultades se creen tiene que crecer y desarrollarse y llenar el mundo ${ }^{16}$.

La sublevación acabó con la muerte del dirigente republicano federal Froilán Carvajal, que fue ejecutado en lbi por las tropas gubernamentales antes de la llegada del indulto y a pesar de las numerosas peticiones que en este sentido se hicieron por parte de los organismos y entidades locales ${ }^{17}$.

Ante estos hechos el Ayuntamiento de Alicante, presidido por E. Maisonnave, dimitía en pleno ante la Diputación Provincial. Esta situación fue utilizada por el gobernador militar para nombrar un Ayuntamiento pro-monárquico e intensificar la acción represiva contra los núcleos republicanos alicantinos con la prohibición de manifestaciones, reuniones y la censura de la prensa ${ }^{18}$.

Cuando se celebraron las elecciones municipales de 1870 volvieron a ser más votadas las listas republicanas. El Ayuntamiento monárquico, que estaba presidido por Miguel Colomer y que contaba entre sus concejales con representantes del con-

15 La Revolución, 19 de octubre de 1869.

${ }^{16}$ El Correo de España, 14 de octubre de 1869.

17 La Revolución, 13 de octubre de 1869.

18 El Correo de España, 14 de octubre de 1869. 
servadurismo local como Blas de Loma y Corradi, Mauricio, Alted y Penalva, propuso la impugnación de las actas electorales basándose en supuestas irregularidades en el proceso de elecciones $^{19}$. La Diputación no aceptó tal impugnación ${ }^{20}$ y el 16 de enero de 1870 vuelve a entrar una corporación municipal republicana encabezada por Maisonnave ${ }^{21}$.

Esta insurrección ahondó aún más la brecha existente entre el sector moderado del partido, representado por Eleuterio Maisonnave y sin la que pedía castigo para los sublevados, y los sectores más radicalizados que abogaban por la lucha armada. En esta última posición el periódico republicano "La Revolución" aplaudía el manifesto de los Diputados republicanos federales, añadiendo:

...y se declara explicitamente que si bien debemos asegurar el triunfo de nuestras ideas en los comicios, en los clubs, en los comités y en todas partes por medio de la enseñanza y de la propaganda pacífica, no debemos por eso renunciar de una manera absoluta a emplear el triste medio de las revoluciones armadas, hoy que los derechos naturales no están aún asegurados y que por la violación de esos mismos derechos habrá necesidad de acudir a la fuerza para rechazar con ella los ataques que en el mismo terreno nos dirijan ${ }^{22}$.

Aunque desde las posiciones moderadas se quiso restar importancia al fusilamiento de Carvajal, la verdad es que su nombre fue utilizado como el de uno de los mártires del federalismo por los grupos más radicalizados del republicanismo alicantino, que exigía que se indultara a los presos federalistas que permanecian encerrados en el castillo de Santa Bárbara desde las revueltas.

En resumen, las sublevaciones federales de octubre supusieron la consolidación de la alternativa moderada propugnada

19 Archivo Municipal de Alicante, Cabildos, 11 de enero de 1870. En lo sucesivo utilizaremos la abreviatura A. M. A.

20 Archivo de la Diputación Provincial de Alicante, Sección de Elecciones, leg. 420.

21 A. M. A., Cabildos, 16 de enero de 1870.

22 La Revolución, 28 de noviembre de 1869. 
por los dirigentes de la Revolución de 1868. Los mecanismos de represión, como hemos visto, sirvieron a ese propósito y así fueron utilizados en un momento en que una fuerte oposición repu. blicana podía poner en peligro la constitución de una nueva monarquía apoyada por los partidos que controlaban el gobierno:

¿Por qué no se levanta la suspensión de garantías constitucionales? por miedo al partido republicano, que sin duda imposibilitaría todo rey, pues bien, prescindiendo de esa monomanía de traerlo, claro está que no podía haber temor y por lo tanto ningún inconveniente en devolver a la nación el ejercicio de los derechos individuales ${ }^{23}$.

A nivel interno del partido, los hechos insurreccionales de octubre también tuvieron consecuencias, en ellos hay que ver el origen de la división en el seno del republicanismo. Aunque la historiografía sobre el tema señala la Declaración de la Prensa como el arranque del proceso de escisión en el partido, serán la sublevación federal del 69 y los planteamientos a favor de la lucha armada como medio para la toma del poder lo que empieza a separar a los dos sectores del republicanismo alicantino, cuyas bases ideológicas sobre la forma de república comienzan a ser radicalmente distintas.

\section{LA «DECLARACION DE PRENSA»}

El fracaso del levantamiento y la represión que siguió produjeron un momento de desconcierto y desorganización en los federales. En 1870 el tema que más preocupaba a la opinión republicana era la reunión de la Asamblea Federal, a celebrar en el mes de marzo. En ella dominarán los federales de provincias, por lo que era inviable cualquier intento de proclamación de una república unitaria, como deseaban algunos sectores del partido.

Entre las resoluciones de la Asamblea del partido figuran aquellas tendentes a esclarecer las posiciones de los republicanos ante el tema federal, así en la resolución primera se dice:

23 Ibidem, 20 de noviembre de 1869. 
La base política del partido republicano federal es y será siempre la fórmula republicana federal, con exclusión absoluta de toda otra fórmula de gobierno, incluso la República unitaria... ${ }^{24}$

En esos momentos grupos federalistas de Alicante seguían manteniendo las tesis de la revolución armada, del derecho de insurrección cuando hubiesen fallado los medios pacíficos de implantar un gobierno republicano ${ }^{25}$.

La reacción de la derecha del republicanismo no se hizo esperar. Esta fracción mantenía un cierto dominio sobre la mayoría de los periódicos republicanos de Madrid a pesar de ser minoritarios aún en la organización del partido. Es en este marco donde se sitúa la "Declaración de la Prensa", por la que los representantes de los periódicos "La Discusión", "El Pueblo", "Gil Blas", "La Igualdad", "La República Ibérica" y "El Sufragio Universal", abogaban claramente por una república unitaria. Fue una declaración antipactista, en contra de $\mathrm{Pi}$ y de su línea "socializante", a la que el Directorio contestó con un manifiesto de condena total por ser contrario al punto primero de las tesis aprobadas en la Asamblea.

Esta manifestación en contra del federalismo sinalagmático se producía por la influencia de Castelar sobre la prensa madrileña, en un momento en que el sector republicano moderado se acercaba a Prim, esperando que éste se decidiese por la fórmula republicana para salvar la inestabilidad política que ponía en peligro la revolución de śeptiembre. En Alicante Maisonnave jugó la baza del unitarismo defendiendo la necesidad de que el partido republicano se alinease con las tesis moderadas de la prensa. Su apoyo a la "Declaración» quedó patente en una exposición que tuvo lugar en el Círculo Republicano de la capital:

Continuando su discurso, dijo que hoy nuestro partido se encuentra dividido en dos bandos: en uno, el verdadero partido republicano, amigo de la integridad nacional, y en otro, los republicanos confederados, separatistas, socialistas...

24 Vera y GonzAlez, E., Pi y Margall y la política contemporánea, Barcelona, 1886, pág. 86.

${ }^{25}$ La Revolución, 4 de mayo de 1870. 
La Declaración, dijo nuestro diputado, nadie la ha combatido de frente por no tener punto alguno vulnerable, y con tal motivo parece quiso suponer que los que tal hacian, eran los terroristas y demagogos que, con sus destemplanzas y exageraciones nos llevarian al caos de donde no saldríamos sino después de muchos siglos de despotismo y tiranía. Algún daño nos hizo esa especie vertida por haber tomado parte en el combate; $y$ si tales calificativos se dirigían a La Revolución, de la cual nosotros somos humildes redactores, lo rechazamos por no ser justos, ni merecerlos ${ }^{26}$.

De forma inmediata, la redacción del órgano de prensa republicano de Alicante, "La Revolución", y algunos otros secto. res importantes del partido se manifestaron en contra de la "Declaración de la Prensan y de cualquier intento de implantar en el país una república unitaria pactada con los conservadores:

En el partido republicano de esta localidad, no puede decirse, sin faltar a la verdad, que los federales de Alicante acepten esa declaración unitaria ni mucho menos que aprueben el cambio de conducta de los diputados Maisonnave y Santamaría. No, y mil veces no ${ }^{27}$.

No es exacta la noticia que ha circulado por esta capital sobre el hecho de haberse arreglado la cuestión de la Declaración de la prensa con el manifiesto del Directorio de nuestro partido. No cabe transacción entre principios distintos y aún diametralmente opuestos.

En puntos referentes a la pureza de la idea federativa no es posible ceder sin que este acto afecte y perjudique gravemente a la integridad del dogma federal. El Directorio, fiel custodio de este dogma y autoridad legitima de nuestro partido, no ha cedido (estamos seguros de ello), no cede, ni cederá jamás un ápice ${ }^{28}$.

La declaración de los seis periódicos de Madrid nos ha dividido, nos ha turbado, sino que supone que la Deciaración del dia 7 está en armonía con las opiniones y los intereses de algunas clases de nuestro partido, o que tiene en su abono trabajos e influencias que no son todavía conocidos del público. finir ${ }^{29}$.

Sea lo que fuere, aquí hay algo grave que conviene aclarar y de-

26 Ibidem, 20 de mayo de 1870.

27 Ibídem, 28 de junio de 1870.

28 Ibidem, 24 de julio de 1870.

29 Ibidem, 10 de agosto de 1870. 
Estas posiciones encontradas llevarán a una crisis en el interior del partido de los republicanos, que no es más que la manifestación de un proceso que se venía gestando desde octubre de 1869. El enfrentamiento se dará entre los militantes más moderados que apoyaban dicha Declaración, y entre los que se cuentan los que formaban el Comité Local, y los militantes federalistas más cercanos a los planteamientos de Directorio. Estos últimos estaban dirigidos por una fracción del Comité Provincial y contaban con el apoyo de la militancia de ciertos clubs locales como el de "Los Radicales", "El Federal" del distrito del Carmen y la "Sociedad Propagandística de San Antón".

Estos clubs publicaron en la prensa local un manifiesto de protesta por la adhesión del Comité Local a la Declaración y convocaron elecciones para formar un nuevo Comité que se ajustara a la línea de la dirección del partido:

\begin{abstract}
El partido republicano federal de esta ciudad aunque merced a las crudas y sistemáticas apologías de ciertos prohombres haya atrevesado fatalmente momentos de duda e indecisión, pero siempre inalterable en sus principios y educación política, hoy como nunca y ajustando su proceder a las preclaras disposiciones del Directorio, siente la viva necesidad de organizarse (...) comprendiendo que la alta e ineludible misión de nuestro Comité, es completamente contradictoria con los principios que sustenta encarnados en la funesta Declaración del 7 de mayo... Declaramos al indicado comité se halla de carácter excluso de su respectiva representación... ${ }^{30}$
\end{abstract}

El nuevo Comité Local, resultante de estas elecciones estaba formado por republicanos federalistas e intransigentes y presidido por Vicente López, que en los sucesos cantonales de julio de 1873 se destacó como miembro de la Junta Revolucionaria de la ciudad que apoyó a los insurrectos de Cartagena. Más tarde el Comité Republicano Federal de la Provincia de Alicante desautorizó a este nuevo Comité Local, declarando ilegal su constitución, pues a pesar de que el Comité Provincial había acordado aceptar al Directorio como única autoridad y representación del partido $^{31}$, existían también en su seno disparidad de criterios y

30 Ibidem.

31 Ibidem, 14 de agosto de 1870. 
José Rizo, representante de Alicante en dicho Comité, habia manifestado sus reparos a la política del Directorio y habia expresado en cierta manera su apoyo a Maisonnave.

Estas decisiones titubeantes del Comité Provincial se debían a las presiones de los núcleos más conservadores del partido, sobre todo del alcalde Maisonnave, que, a raíz de tales acontecimientos, dimitió de su cargo ${ }^{32}$, utilizando su prestigio en la ciudad y en el propio partido para atraerse a los militantes más indecisos, que hasta entonces no se habian inclinado hacia ninguna de las opciones en litigio. Desde este momento, coincidiendo con la aparición del diario republicano "El Municipion y la desaparición de "La Revolución", Maisonnave irá consolidando su control sobre el aparato del partido.

\section{REPUBLICANISMO Y CLASE OBRERA}

Hemos de señalar ahora un aspecto fundamental del republicanismo alicantino, su conexión con los problemas sociales y en concreto con el movimiento obrero. Desde el principio el republicanismo no olvidó ni relegó la cuestión social, puesto que su propia militancia se nutría, en parte, de sectores del proletariado urbano, jornaleros, artesanos y pequeña burguesía en trance de proletarización. Es un momento en que todavía la clase obrera presta su apoyo al republicanismo, especialmente influenciado por la línea pimargalliana de reparto de la propiedad y en contra de las industrias monopolísticas, ideología que, como ha señalado J. Romero ${ }^{33}$, está muy en consonancia con la estructura económica que se estaba consolidando en el País Valenciano, tendente hacia la pequeña y mediana propiedad agraria y hacia la pequeña empresa industrial. En estos años la clase obrera también se verá influenciada por el auge del movimiento cooperativista que va a ser asumido plenamente por ciertos sectores del republicanismo.

32 Ibídem.

33 Romero, J., "Notes per a l'estudi dels origens del moviment obrer al País Valencià (1868-1909)", Arguments n. 3, L'Estel, Valencia, 1977. 
La vinculación de los núcleos artesanales y obreros alicantinos con las primeras asociaciones obreras españolas, en concreto con la Dirección Central de Sociedades Obreras de BarceIona, se realizó a través del periódico "La Revolución" que contaba entre sus colaboradores con Fernando Garrido, prestigioso líder del obrerismo catalán ${ }^{34}$.

En abril de 1870 un grupo de militantes republicanos, de claro matiz federalista, tomaron la iniciativa de formar una sociedad cooperativa, y así su promotor, Bartolomé Pons, se dirige al proletariado alicantino en el siguiente manifiesto:

Ciudadanos: el que hoy os dirige la palabra es un proletario como vosotros hijo del trabajo, pertenece, en consecuencia, a la gran familia desheredada, mi constante anhelo, mis deseos de siempre han sido y serán contribuir con mi insuficiencia al mejoramiento de la clase a la que me honro en pertenecer (...). Ya habréis visto anunciado es este periódico el proyecto de formar una sociedad cooperativa en esta localidad. Este pensamiento, iniciado por algunos ciudadanos, es de una trascendencia para la clase trabajadora, por cuanto su tendencia es dar protección al arte y atender en cuanto pueda al socorro de los socios enfermos y faltos de jornal. Además de este pensamiento hay también el de establecer una tienda de comestibles para el consumo de los socios, en donde éstos podrán encontrar un beneficio en los precios y calidad en los géneros ${ }^{35}$.

La iniciativa era muy importante porque suponía un primer paso hacia la asociación obrera, en una fase en la que todavía no se ha roto el colaboracionismo entre el proletariado y partidos de la pequeña y mediana burguesía como el republicano, e incluso se introduce el elemento nuevo de formar una cooperativa de consumo.

La sociedad se denominó "Sociedad Cooperativa y de Protección al Arten, y poco después de su creación contaba ya con 198 socios que representaban 730 acciones emitidas hasta entonces $^{36}$. En el Consejo de Administración ostentaba la dirección Juan Mas y Dols, como vicedirector actuaba Amando Albe-

34 Durante los años 1869 y 1870 aparecen con cierta frecuencia en este periódico comunicados y cartas de la Dirección Central de Sociedades Obreras.

35 La Revolución, 4 de mayo de 1870.

36 Ibídem, 27 de mayo de 1870. 
rola y como tesorero Antonio Esquembre. El resto del Consejo lo formaban Manuel Santandreu y Ramón Solves como secretarios, Primitivo Carreras como contador y ocupando las vocalías, Bartolomé Pons, Evaristo Fajardo, Rafael Gallud y Vicente Alemañ entre otros.

Como vemos, aunque la dirección de la sociedad estuviese en manos de republicanos moderados, quizás por su mayor prestigio social, la iniciativa había partido de sectores obreristas y de extremado federalismo, precisamente los que figuran en las vocalías. También es de señalar la no participación en esta sociedad de los núcleos republicanos más conservadores si exceptuamos a Amando Alberola y Juan Mas y Dols; en la lista de socios no aparecen nombres tan vinculados a la vida política y cultural alicantina como Manuel Ausó, Román Bono o Eleuterio Maisonnave. Esto nos indicaría el divorcio existente entre las tendencias republicanas que se acentúa aún más si cabe en lo que se refiere a la cuestión social.

Estos grupos, en consonancia con la línea moderada de Castelar, empezaban a temer la radicalización social por el avance del movimiento obrero, que podía llenar de contenido social el proyecto republicano dando un mayor alcance a la tibia política reformista republicana.

\section{HACIA LA REPUBLICA}

Todos los problemas internos del partido republicano quedarán relegados a un segundo plano de momento ante la proclamación de Amadeo de Saboya como rey de España, el monarca constitucional que representaba la salida moderada que habían buscado Prim y los partidos dominantes de la revolución. Ante estos hechos, todos los esfuerzos republicanos van a ser dirigidos a la crítica de la nueva situación política. Estos ataques a la monarquia, que pronto adquieren un carácter de xenofobia ${ }^{37}$, serán de mayor dureza cuando se ponga en evidencia la debilidad de la nueva institución monárquica.

37 Ibidem, 28 de diciembre de 1870. 
En realidad, aunque aparezca en segundo término, la crisis interna del partido republicano seguía latente. Con la instauración de la monarquía se patentizó la separación entre benévolos e intransigentes, pues, mientras los primeros eran partidarios de apoyar al gobierno de Zorrilla, los intransigentes se oponian a cualquier tipo de colaboración con los gobiernos de Amadeo I.

Los federalistas, con una posición más radical, desconfiaban de los posibles acuerdos que se pudieran tomar desde la dirección del partido con los grupos conservadores en los que en estos momentos se asentaba la monarquía.

Con la decisión de la Asamblea Federal de participar en las elecciones generales de abril de 1872 , se rechazaba definitivamente cualquier intento de implantar la república por medios violentos, y se legitimaba el juego democrático de la monarquía. Estas posiciones de la Asamblea crearon un cierto malestar entre los republicanos de la periferia, concretamente en Alicante se desató una campaña de prensa muy demagógica y radical ante la convocatoria electoral. En estos artículos aparecen con insistencia llamadas a evitar cualquier tipo de corrupción y alusiones a Amadeo I como representante de una monarquía despótica, así mismo se utilizará un lenguaje interclasista llamando a los obreros a las urnas, para que apoyen las candidaturas republicanas prometiéndoles que con la República llegaría la emancipación general del proletariado ${ }^{38}$.

Estas elecciones, en la ciudad de Alicante, fueron ganadas por los republicanos con un escaso margen de votos. En las mesas electorales situadas en la ciudad son más votadas las listas republicanas, mientras que en la huerta de Alicante se da una inclinación al voto conservador. Así, en las zonas con predominio de obreros y artesanos (San Antón, Barrio del Carmen, San Francisco), donde se organizan los clubs federalistas, vencen los republicanos, frente a zonas como Santa Faz, San Vicente o La Alcoraya, en las que el partido monárquico dobla en ocasiones los votos conseguidos por el partido republicano ${ }^{39}$.

38 El Municipio, periódico republicano federal, 27 de marzo de 1872.

39 Ibídem, 4 y 5 de abril de 1872; El Constitucional, periódico liberal de Alicante, 4 y 6 de abril de 1872. 
La demagogia del discurso republicano denotaba la falta de realismo de las organizaciones locales, mientras que la visión política de los benévolos era mucho más coherente, pues se daban cuenta de que la única salida posible era un' acercamiento a los radicales, postura que más tarde daría el triunfo a los objetivos republicanos ${ }^{40}$.

A partir de los poderes otorgados por la III Asamblea Federal, Pi y Margall va a elegir un Directorio en el que están representados también los miembros intransigentes, lo que podía considerarse como un intento de evitar una escisión en el partido. Los sucesos insurreccionales de El Ferrol harán fracasar esta tentativa, provocando un cambio de actitud en los republicanos alicantinos ya que desde entonces amplios sectores se criticaron duramente las posiciones intransigentes ${ }^{41}$, y así veremos como el Comité Local se adhiere a las posturas del Directorio de condena a los sublevados ${ }^{42}$. En este sentido hay que destacar que mientras para $\mathrm{Pi}$ y Margall el mayor peligro eran los carlistas y los grupos pro-alfonsinos, para el grupo de Castelar y Maisonnave lo constituía la intransigencia federal unida al radicalismo social del movimiento obrero.

En noviembre de 1872 se darán tímidos movimientos de partidas republicanas en las comarcas del Vinalopó y en la zona industrial de Alcoy, pero serán criticadas acervamente por los dirigentes del partido en Alicante ${ }^{43}$.

Todo esto nos indica un giro de gran parte de la militancia republicana hacia posturas más moderadas, de respeto a la legalidad vigente, rechazando cualquier intento de sublevación armada, ante la inminente caída de la monarquía y la posible proclamación de la República. Por ello presentarán a los intransi-

40 Hennesy, C. A. M., La República Federal en España: Pi y Margall y el movimiento republicano federal. 1868-74, Madrid, 1967, pág. 173.

41 El Municipio, 31 de octubre de 1872.

42 Ibldem, 8 de noviembre de 1872.

43 Ibídem, 28 de noviembre de 1872. 
gentes como aliados de la reacción, acusándoles de terroristas y adoptarán nuevas actitudes, presentándose como un partido de orden, legalidad y moderantismo.

En definitiva, la dirección del partido republicano cambió de estrategia cuando se dio cuenta de la crisis de la monarquía y de lo que era más evidente, que los grupos monárquicos carecían de otra solución de recambio político que no fuera la República.

En Alicante, a la vez que se presenta al partido como una organización fuertemente implantada y compuesta de hombres honrados y de orden, se preconiza la disciplina dentro de sus filas y la unidad del partido, rompiendo con la inestable imagen que producían la disensiones en el seno del mismo ${ }^{44}$.

Las constantes llamadas a la unidad indicaban que el principal problema con que se encontraba la organización era el de las divisiones internas, provocadas, en parte, por la heterogeneidad de las fuerzas sociales que lo apoyaban. Esto cristalizará en las diferentes tendencias políticas que en su seno van a coexistir y que en los albores de la República amenazan con escindir a İos republicanos, dándole a su formación política un carácter de permanente fragilidad.

A modo de conclusión, podemos señalar que desde 1868 en el republicanismo alicantino se va a iniciar un proceso de disgregación del partido en dos tendencias, por un lado tendremos a los federalistas, también llamados intransigentes, y por otro a un sector relacionado con la política de Castelar y Maisonnave de moderantismo extremo, que en los últimos meses de la República llegará a adquirir un auténtico carácter de conservadurismo social.

En Alicante esta división responde, en cierta manera, a una diferenciación de origen social. Los militantes que apoyaban las tesis del federalismo pertenecen a sectores de pequeña burguesía muy radicalizada, artesanos y obreros, por el contrario los moderados son representantes de otro status social, de un sec-

44 Ibidem, 3 de enero de 1873. 
tor de burguesía de negocios urbanos y comerciales muy vinculada a intereses agrarios que, a diferencia de lo que se podia pensar, no apoyan a los partidos monárquicos sino que optan políticamente por una república unitaria y conservadora, lejos de cualquier tipo de reforma económico-social que pudiese modificar esencialmente el sistema.

El distanciamiento de estos dos grupos se produce básicamente en dos temas: la configuración y organización del estado liberal, desde donde se plantean dos alternativas, república federal o república unitaria, y la cuestión de las reformas sociales. Es este último un problema esencial pues la utopía federalista de una sociedad donde predominase la pequeña propiedad y se lograra una asociación del trabajo y el capital suponía una política reformista radical que nunca podría ser aceptada por la tendencia más conservadora del partido.

Por último, destacar como el sector dirigido por Maisonnave va imponiendo sus opiniones hasta conseguir prácticamente el control del partido y como en consecuencia el movimiento obrero irá retirando su apoyo al republicanismo y comenzará a elaborar sus propias alternativas. 